\title{
Heat transport in open-cell foams: CFD analysis of artificial heat sources vs. fully resolved exothermal reactions
}

\author{
Christoph Sinn ${ }^{1}$, Jonas Wentrup ${ }^{1}$, Georg Pesch ${ }^{1}$, and Jorg Thoeming ${ }^{1}$ \\ ${ }^{1}$ University of Bremen
}

October 21, 2020

\begin{abstract}
Catalytic structured foam reactors show promising characteristics for process intensification such as low pressure drop, high specific surface area, and remarkable heat transport. Especially for the design of small-scale dynamically operated reactors the understanding of heat transport is crucial. With computational fluid dynamics (CFD) we can thoroughly investigate the thermal field of the coupled gas/solid under reaction conditions and understand heat transport in structured reactors. In the past, we mimicked the heat production during exothermal reactions with uniformly distributed volumetric heat sources in the solid. Here, we compare thermal fields of such simplifications with full-model calculations using the strongly exothermal CO oxidation as model reaction. We find that heat flows of the reaction and of artificial heat source calculations match well and reliable mean temperature increases can be computed. This helps to determine heat removal mechanisms and estimate thermal stress.
\end{abstract}

\section{Hosted file}

manuscript_S_vs_dHr.pdf available at https://authorea.com/users/369224/articles/488151-heattransport-in-open-cell-foams-cfd-analysis-of-artificial-heat-sources-vs-fully-resolvedexothermal-reactions 